Article

\title{
The Knowledge Mapping of Concentrating Solar Power Development Based on Literature Analysis Technology
}

\author{
Qimei Chen ${ }^{1,2, *}$, Yan Wang ${ }^{3}{ }^{(\mathbb{C}}$, Jianhan Zhang ${ }^{3}$ and Zhifeng Wang ${ }^{2,3, *(1)}$ \\ 1 National Science Library, Chinese Academy of Sciences, Beijing 100190, China \\ 2 University of Chinese Academy of Sciences, Beijing 100049, China \\ 3 Institute of Electrical Engineering, Chinese Academy of Sciences, Beijing 100190, China; \\ wangyan955@126.com (Y.W.); jhzh@tsinghua.edu.cn (J.Z.) \\ * Correspondence: chenqm@mail.las.ac.cn (Q.C.); zhifeng@vip.sina.com (Z.W.); \\ Tel.: +86-1861-031-3267 (Q.C.); +86-1370-132-7862 (Z.W.)
}

Received: 13 March 2020; Accepted: 31 March 2020; Published: 17 April 2020

\begin{abstract}
Decreasing the levelized cost of renewable energy and improving the stability of power systems are the key requirements for realizing the sustainable growth of power production capacity. Concentrating solar power (CSP) technology with thermal energy storage can overcome the intermittent and unstable nature of solar energy, and its development is of great significance for the sustainable development of human society. In this paper, topic discovery and clustering were studied using bibliometric, social network analysis and information visualization technology based on the Web of Science database (SCI-Expanded) and the incoPat global patent database. The technology searched for papers and patents related to CSP technology to reveal the development trends of CSP technology and provide the references for related technical layout and hot spot tracking. The results show that the global output of CSP technology papers has continued to grow steadily, whereas the number of patent applications showed a significant downtrend. CSP technology, which is at the initial stage of commercialization, still needs technological breakthroughs. Technological innovation that integrates thermal engineering, control engineering, physics, chemistry, materials, and other disciplines may become an effective path for CSP technology development in the future. CSP technology research shows increasing research and development trends in high-temperature receivers, phase-change thermal energy storage, the overall performance of thermal power generation systems, and a development trend from a single technology to multi-energy complementary systems.
\end{abstract}

Keywords: concentrating solar power; renewable energy; domain development trend; bibliometrics; knowledge mapping

\section{Introduction}

Because of the devastating impact of fossil fuel consumption on the environment and continuous growth in global power demand, the development of alternative energy has become a hot topic for many governments and energy stakeholders. There is an urgent need to explore alternative energy technologies and systems for sustainable development, improve the power generation capacity of renewable energy, and realize sustainable growth in power production capacity [1,2]. Solar energy is one of the cleanest forms of renewable energy, with a wide range of uses, and large-scale sustainable development, is expected to become an alternative to conventional generation methods using coal power, natural gas, and hydropower [3-7]. However, its randomness and intermittent characteristics greatly affect its application. Among various solar energy technologies, concentrating solar power (CSP) is an increasingly attractive technology. CSP with thermal energy storage (TES) can effectively overcome 
its intermittent nature and offer energy dispatchability to adapt the electricity power production to the curve demand $[8,9]$. Considering the high energy saving and high energy efficiency, CSP plants were predicted to produce a global electricity contribution of $7 \%$ by the year 2030 and $25 \%$ by the year 2050 [10], and could meet up to $6 \%$ of the world's power demand by 2030 and $12 \%$ by 2050, according to the prediction of the European Solar Thermal Power Association [11].

CSP is a technology that uses mirrors to concentrate and reflect sunlight onto receivers, converting solar energy into thermal energy. This thermal energy can then be used to produce electricity via a turbine (e.g., steam, air, or supercritical carbon dioxide) or other type of heat engine that drives a generator [12]. When combined with thermal storage capacity, CSP plants are able to generate electricity during cloudy periods or for hours after sunset or before sunrise. This ability to store solar energy makes CSP a flexible and dispatchable source of renewable energy [13]. Additionally, for instance, one megawatt of installed CSP avoids the emission of 688 tons per year of $\mathrm{CO}_{2}$ compared to a combined cycle system, and 1360 tons per year of $\mathrm{CO}_{2}$ compared to a coal/steam cycle power plant. One square mirror in the solar field produces $400 \mathrm{kWh}$ of electricity per year, avoids 12 tons of $\mathrm{CO}_{2}$ emission, and contributes to 2.5 tons savings of fossil fuels during 25-year operation lifetime [14].

In CSP plants, electrical power is generated by concentrating solar radiation. Generally, CSP plants consist of several components such as solar concentrators, receiver, steam turbines, and electrical generators. The main types of CSP technologies are linear Fresnel reflector CSP, central receiver (power tower) CSP, parabolic dish CSP, and parabolic trough CSP [12].

1. Linear Fresnel CSP produces a linear focus on a downward-facing fixed receiver mounted on a series of small towers. Long rows of flat, or slightly curved, mirrors move independently on one axis to reflect the sunlight onto the stationary absorber tube and heat transfer fluid (HTF) to generate electricity. The cost of linear Fresnel CSP is lower than that of other CSP systems, but the heat-power efficiency is lower.

2. Central receiver CSP is used with many heliostats that track solar movement and reflect sunlight onto a receiver located at the top of a tower. HTF passes through the receiver and is heated to a high temperature. The high-temperature HTF is fed into a turbine or generator to generate electricity, directly or indirectly. Central receiver CSP has the greatest thermal-electric conversion efficiency (in the power block) among the four types of CSP.

3. Parabolic dish CSP uses parabolic point-focus concentrators (also called reflectors). The concentrators are placed in an assembly with a two-axis tracking system that follows the sun. At the focal point, for efficient power conversion, a Stirling/Brayton engine is placed with an electrical generator to utilize the concentrated heat at the receiver.

4. Parabolic trough CSP is used with linear parabolic mirrors (also called reflectors) to track sunlight on one axis and reflect solar radiation to a linear focus on an absorber tube, which heats HTF and generates electricity. Parabolic trough systems, achieving thermal energy collection via evacuated tube receivers, are the first commercially operating CSP technology. As of 2018, 90\% of the CSP in commercial operation is parabolic trough plant [13].

A brief comparison among the above technologies is illustrated in Table 1. In Table 1, operating temperature means the plant can reached the temperature during concentrating sunlight, concentration ratio is the ratio of the ratio of the area of aperture to the area of the receiver, average annual efficiency is the efficiency of sunlight to electricity, and installed capacity means the maximum capacity of one plant. The CSP technologies have different characteristics, development levels, application scopes, and development prospects. 
Table 1. Comparison of CSP technologies [12,15].

\begin{tabular}{cccccc}
\hline CSP Type & $\begin{array}{c}\text { Operating } \\
\text { Temperature }\left({ }^{\circ} \mathbf{C}\right)\end{array}$ & $\begin{array}{c}\text { Concentration } \\
\text { Ratio }\end{array}$ & $\begin{array}{c}\text { Thermal Storage } \\
\text { Suitability }\end{array}$ & $\begin{array}{c}\text { Average Annual } \\
\text { Efficiency }\end{array}$ & $\begin{array}{c}\text { Installed } \\
\text { Capacity }\end{array}$ \\
\hline Linear Fresnel & $50-300$ & 200 & Suitable & $8-11 \%$ & $30-150 \mathrm{MW}$ \\
Central receiver & $300-1000$ & $300-1000$ & Highly suitable & $17-35 \%$ & $10-600 \mathrm{MW}$ \\
Parabolic dish & $120-1500$ & $1000-3000$ & Difficult & $25-30 \%$ & $5-25 \mathrm{KW}$ \\
Parabolic trough & $200-400$ & $50-90$ & Suitable & $15 \%$ & $50-600 \mathrm{MW}$ \\
\hline
\end{tabular}

According to the latest data from the International Energy Agency, at the end of 2019, the total CSP capacity is $9267 \mathrm{MW}$. The total installed capacity of CSP globally has attained around 6.2 MW. Spain, the United States of America (USA), and China topped the list of countries with CSP plant capacity exceeding $1 \mathrm{GW}$ [16].

As mentioned above, CSP technology can realize the transformation from sunlight to thermal to electricity, which is composed of four main elements: Concentrators (optical field), receivers (including receivers and absorber tubes), thermal storage (including HTF and storage material), and thermal power conversion. For different types of CSP, the key components have different structure, characteristic, and performance. In order to optimize the component structure [17-21], improve the mechanical performance, control the accuracy of equipment [22-24], improve the energy conversion efficiency [25-36], and reduce the Levelized Cost of Electricity (LCOE), researchers around the world have already conducted substantial research on key technology [37,38], applications [39-41], system design [39,42], and economics of CSP $[13,43-45]$.

This paper presents a topic identification and clustering of results related to CSP technology by means of bibliometric and social network analysis using the Web of Science (WoS) scientific database and the incoPat patent database as sources. The analysis of technological research and applications studies the distribution of works by discipline, countries, organization, and topic, providing a multidimensional review and discussion to comprehensively understand the overall development status of CSP. Additionally, social network and information visualization technology were used to reveal the development trends of CSP technology and provide the references for related technical layout and hotspot tracking. Therefore, the purpose of this paper was to help for researchers working in this field to collect the main knowledge about the CSP and related systems, present an extensive literature survey, and define current state-of-the-art and future research challenges.

\section{Data Resources and Research Methodology}

\subsection{Data Resources}

In this study, technical keywords (such as concentrating solar power, power tower CSP, parabolic trough CSP, parabolic dish CSP, solar collector, solar receiver, and heliostat) were used as index words to collect papers and patents on CSP technology, and keywords such as thermochemistry, water heater, and refrigeration were excluded.

The data on papers were taken from the WoS Core Collection database (SCI-Expanded) of Clarivate Analytics company. The database contains more than 8000 influential academic journals in more than 170 disciplines, including natural science, engineering, technology, and clinical medicine, and the earliest journals date back to 1900. By December 2019, 5121 SCI papers were retrieved using the keywords related to CSP technology as the main index words. The keywords and abstracts of the papers were also collected, as well as the year of publication, source journal, country, organization, and author of the papers.

The patent data were taken from the incoPat global patents database of Beijing incoPat Co., Ltd. Information on more than 100 million patents were collected by the incoPat company from 120 countries/ institutions/regions. The data were purchased from the intellectual property authorities and commercial institutions of the various countries, and the earliest patents date back to 1782. By December 2019, 
5143 global patents were retrieved, including the title, abstract, and claims of the patent specification, as well as the year of application, applicant, inventor, legal status, receiving country, claim, patent classification number, and so on.

\subsection{Methodology}

Based on the data on papers and patents, combined with bibliometrics and social network analysis methods, this study conducted bibliometric network analysis and constructed a domain knowledge map to reveal the research and application status and development trends of solar thermal power generation technology.

The statistical method of bibliometrics has proved to be a useful tool to quantitatively assess trends and patterns of academic literature, which was used to analyze the annual output trends for papers and patents, the performance of countries and regions, the important institutes and research and development personnel, and the technology distribution [46,47]. It is effective to combine bibliometrics and social network analysis to investigate specific field of science [48]. Recent studies used bibliometric and social network analysis to explore the scientific literature on important CSP topics $[44,49]$.

In this paper, social network analysis methods were used to construct network representations based on the document knowledge units, and the "3D Patent Sand Table" analysis function of the incoPat database and the knowledge map of VOSviewer were used for visualization analysis. The 3D Patent Sand Table is a 3D visualization tool for patent strategic analysis, which uses an algorithm based on the semantic keywords and technical keywords extracted from the title, abstract, and claims of patent documents, to construct semantic clusters. Using 3D Patent Sand Table to do simulation deduction, this paper revealed on the hotspots of patent layout and primary R\&D directions. VOSviewer is a free software tool for creating maps based on network data and for visualizing and exploring these maps. This software allows for the creation, visualization, and exploration of maps based on bibliometric network data. The output results are displayed in clusters to allow for clear visualization of the existing connections among the bibliometric data [50]. This paper mainly used the four functions of VOSviewer: (1) Information input on the paper title, abstract, and keywords downloaded from the WoS database; (2) term co-occurrence analysis; (3) extraction of the knowledge relationship between documents; (4) formation of a clustering view [51].

\section{Overall Development Trend of Solar Thermal Power Generation Technology}

\subsection{Analysis of Time Trend}

The output trend of papers and patents can reflect the research and development in specific fields to a certain extent and capture the change of focus in research and applications in each period at a macro level. Figure 1 shows the annual output of papers and patents related to CSP technology. It shows that the output trend of papers and patents related to CSP technology can be divided into three periods.

The first period was before 2006. During this period, the annual number of papers and patents about CSP was very small (less than 100), and the annual number of papers was higher than the number of patents. The second period was from 2006 to 2012. During this period, the number of patents increased very rapidly. In 2007, the number of patents exceeded 100 per year, and the number of patent applications reached a peak of 636 per year in 2012. The growth period of CSP papers began in 2007. In 2010, the annual number of CSP papers exceeded 100 for the first time and maintained stable growth. However, during the second period, the number of patents was higher than that of papers, indicating that CSP technology had become a practical technology based on industrial applications. The third period is from 2013 to the present. During this period, the annual number of patents began to decrease, and the downward trend was very significant. The number of patent applications related to technology commercialization. CSP is in the initial stage of commercialization, which is affected by many factors, such as political, market, and technological self. CSP technology economically is one of the major influence factors. Furthermore, the patent data are incomplete after 2018 for the patents' confidentiality 
period (18 months), and there was a delay in adding data to the database. However, the number of papers continued to increase, and exceeded 700 in 2019, despite the delay in adding papers to the database, and the paper data are incomplete in 2019. Observing the increasing trend in the number of papers, the number of papers about CSP technology is likely to continue to increase in the future, showing an obvious increasing trend.

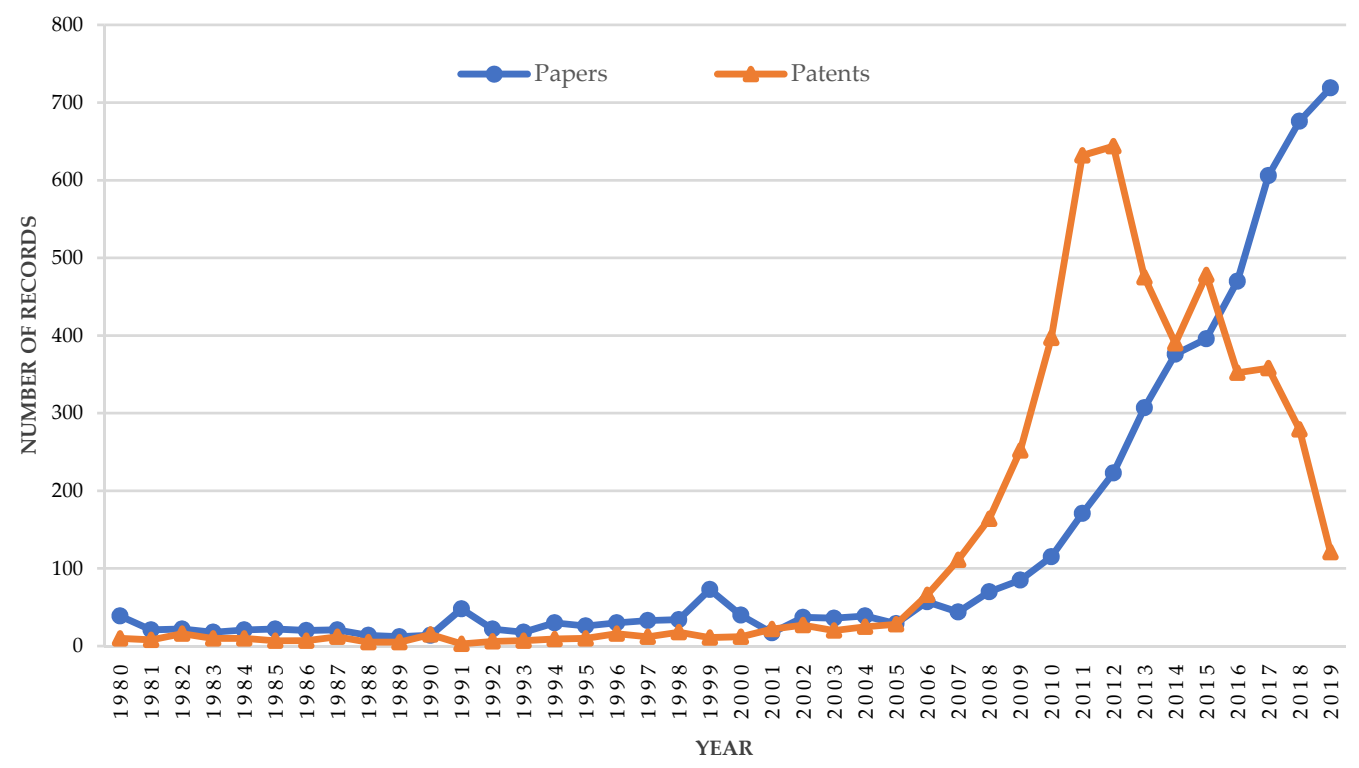

Figure 1. Annual output of papers and patents related to CSP technology.

Figure 1 also shows that, in the field of CSP, technology and science are developing interactively. Scientific research is the basis of technological innovation and serving for industrial application. When the first commercial CSP project was launched in Spain in 2006, CSP technology was considered as a new technology that could be practical and create wealth. This stimulated the lagging growth trend of academic research along with patent technology, and a large number of academic research studies have also promoted the continuous innovation, maturity, and implementation of CSP technology.

\subsection{Analysis of Technological Research and Applications}

\subsubsection{Discipline Distribution of Research Papers}

Each record cited by the WoS Core Collection has a discipline to identify the subject category of the source publication to which the document belongs. There are 252 subject categories in the core collection of WoS.

CSP technology relates to 82 disciplines and has interdisciplinary characteristics, according to the subject categories of the WoS. In the current study, the discipline of a paper was determined by the subject category of the journal in which the paper was published. Because one journal belongs to many disciplines, one paper could also belong to multiple disciplines. Table 2 shows 12 disciplines in which the number of papers was greater than 100, and the total number of papers in each discipline.

The total number of papers in the 12 disciplines was 4715 , which was about $92 \%$ of the total number of papers in the entire CSP field. Table 2 indicates that $70 \%$ of the papers belonged to the energy and fuels field. The number of papers in engineering fields (including mechanical engineering, environmental science and sustainable development, chemical engineering, and electrical and electronic engineering) displays the research characteristics of the basis of applications and high technology. The development of CSP technology has focused on engineering applications, and theoretical research has been conducted using practical applications as the goal. 
Table 2. Discipline distribution of CSP research papers (for disciplines with more than 100 papers).

\begin{tabular}{cccc}
\hline Rank & Subject & Number of Papers & Proportion of Total Papers/\% \\
\hline 1 & energy \& fuels & 3573 & 69.77 \\
2 & thermodynamics & 1240 & 24.21 \\
3 & engineering, mechanical & 933 & 18.22 \\
4 & mechanics & 788 & 15.39 \\
5 & green \& sustainable science \& technology & 667 & 13.02 \\
6 & engineering, chemical & 474 & 9.26 \\
7 & materials science, multidisciplinary & 455 & 8.88 \\
8 & physics, applied & 379 & 7.40 \\
9 & optics & 183 & 3.57 \\
10 & environmental sciences & 161 & 3.14 \\
11 & chemistry, physical & 149 & 2.91 \\
12 & engineering, electrical, \& electronic & 129 & 2.52 \\
\hline
\end{tabular}

\subsubsection{Technology Distribution of Patents}

Patents are important outputs of technology innovation, and the distribution of patents reflects the technology application field. International Patent Classification (IPC) is an international general patent classification and searching tool, which is necessary for all countries in the world. IPC defines categories according to the technology topics and forms a complete stepwise classification system, according to departments, divisions, large categories, small categories, large groups, and small groups. Different IPC numbers represent different types of technical topics. Figure 2 and Table 3 show the IPC subdivision categories for which the number of CSP patents is greater than 100. The IPC subdivision can reveal the direction of patent research to some extent. Figure 2 and Table 3 also show that CSP patents focused on central receivers, electricity generation systems, optic systems, heat transfer, control systems, and new materials. The distribution of patents is similar to that of papers in the CSP field. It can be observed that CSP has followed parallel routes and experienced mutual promotion of basic research and technological development in the fields of scientific and technological innovation.

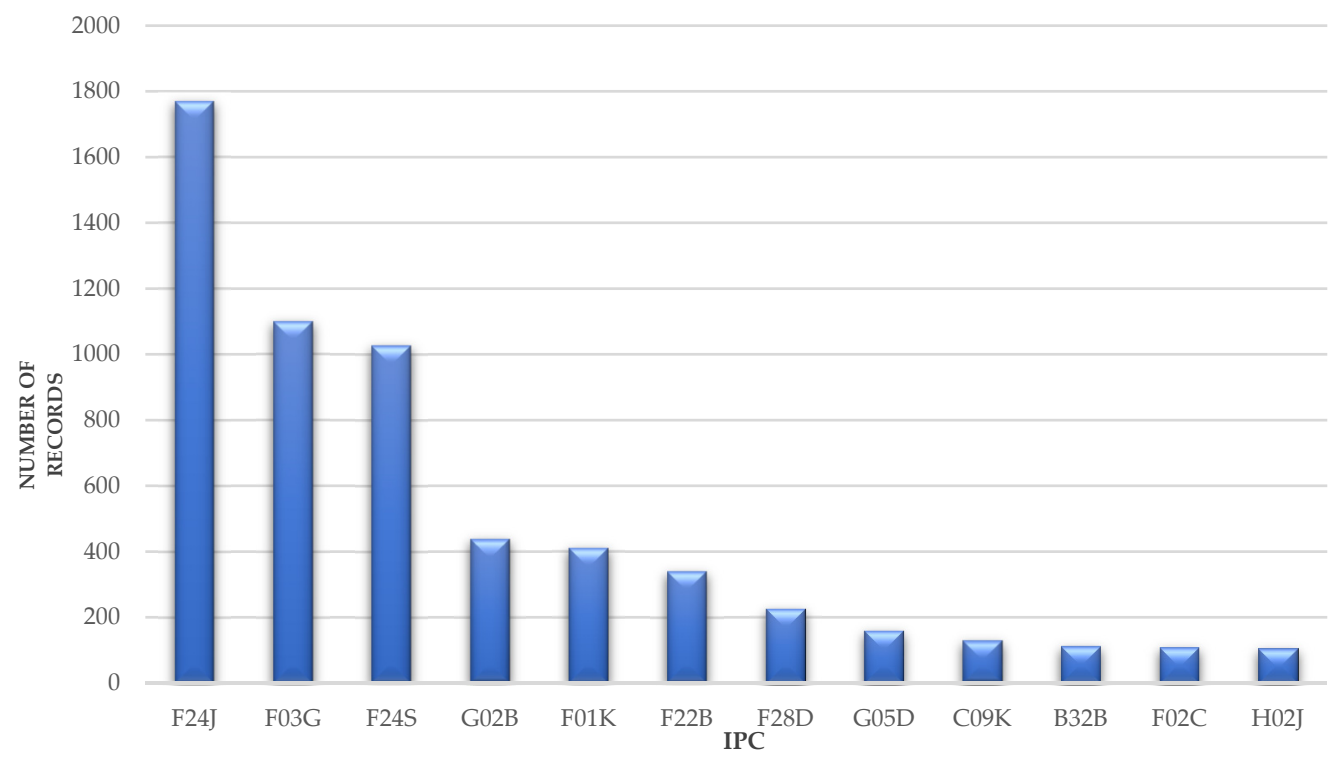

Figure 2. International Patent Classification of CSP technology (for classes with more than 100 patents). 
Table 3. International Patent Classification of CSP technology (for classes with more than 100 patents).

\begin{tabular}{|c|c|c|}
\hline IPC & Number of Patents & $\begin{array}{c}\text { Proportion of } \\
\text { Total Patents/\% }\end{array}$ \\
\hline F24J (Not including the heat generation and application in other categories, such as solar heaters) & 1769 & 34.40 \\
\hline F03G (Elastic, gravity, inertia or similar engines) & 1099 & 21.37 \\
\hline F24S (Solar heat collector, solar heat system) & 1027 & 19.97 \\
\hline G02B (Optical element, system or instrument) & 438 & 8.52 \\
\hline F01K (Steam engine; steam storage; engine not included in other categories) & 410 & 7.97 \\
\hline F22B (Method of steam generation, steam boiler) & 340 & 6.61 \\
\hline F28D (Heat exchanger which not including other subdivision categories) & 226 & 4.39 \\
\hline G05D (Control or adjust system of un-electricity variation) & 160 & 3.11 \\
\hline C09K (All kinds of applicated materials not including in other categories) & 130 & 2.53 \\
\hline B32B (Layered products, i.e., thin layers of flat or non-flat) & 113 & 2.20 \\
\hline F02C (Gas turbine) & 108 & 2.10 \\
\hline H02J (Circuit equipment or system using providing or distribution electricity; electricity storage system) & 105 & 2.04 \\
\hline
\end{tabular}

\subsection{Analysis of Countries and Regions}

\subsubsection{Main Countries of SCI Paper Publication}

By analyzing the number of papers in different countries and regions, we were able to understand the major countries and regions in which research on CSP technology has been conducted. CSP research papers come from 97 countries and regions, and the 10 countries with the largest numbers of papers are China, the USA, Spain, Germany, India, France, Australia, Italy, the United Kingdom (UK), and Iran. The annual publication trends of these countries are shown in Figure 3. The USA, Spain, Germany, France, and Japan began to research CSP in the 1970s, but for China and India, SCI papers were first published about 2000. In 2009, the number of CSP papers from China surpassed the number from the USA for the first time, and China has continued to publish the most CSP papers in the world. China is the only country with more than 1000 publications, accounting for about $20 \%$ of the global total. China, the USA, and Spain are the three main contributors of CSP papers. The output of the three countries accounts for about half of the global CSP papers.

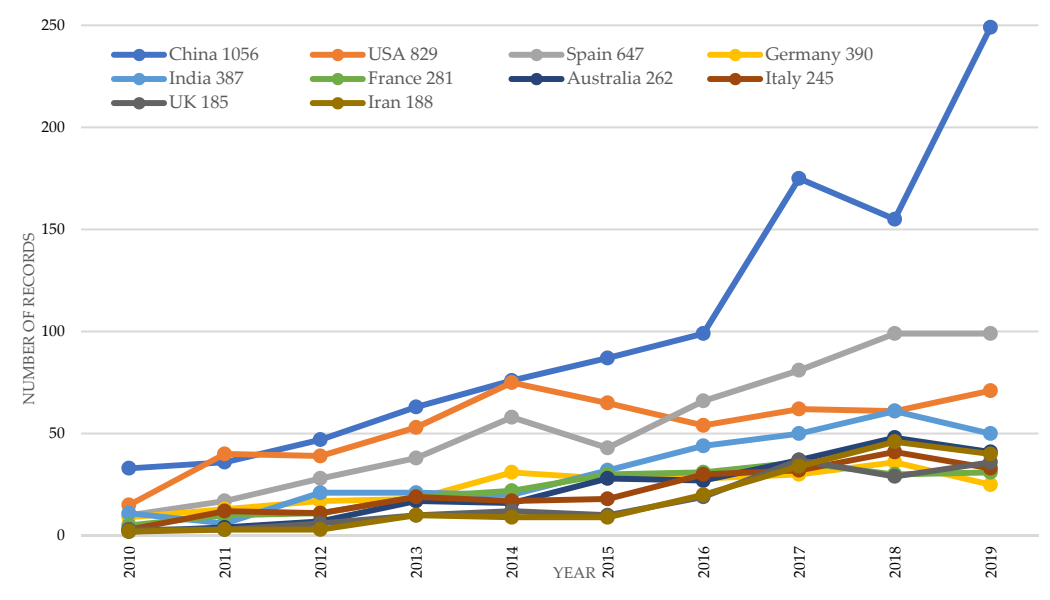

Figure 3. Annual output of CSP papers for each country.

\subsubsection{Main Countries and Regions of Patents}

By analyzing the number of patent applications of specific fields in different countries and regions, we discovered the important target markets of technology applications. Table 4 shows the main countries and regions that accepted CSP technology patents. The global leaders of CSP include the USA, which was the first country to construct a CSP demonstration power station, and Spain, which ranks first with the largest installed capacity of CSP plants. However, developing countries, such as China and India, are rising through active investment and are becoming the most active zone for CSP patents. Until 2019, the number of CSP patents accepted in China accounted for 30\% of the global CSP patents. 
Table 4. Countries/Regions of CSP technology (for countries/regions with more than 100 patents).

\begin{tabular}{ccc}
\hline Countries/Regions & Number of Patents & Proportion of Total Patents/\% \\
\hline China & 1559 & 30.37 \\
USA & 576 & 11.22 \\
WIPO (World Intellectual Property Organization) & 555 & 10.81 \\
Japan & 416 & 8.10 \\
Germany & 343 & 6.68 \\
EPO (European Patent Office) & 295 & 5.75 \\
India & 180 & 3.51 \\
Australia & 138 & 2.69 \\
South Korea & 122 & 2.38 \\
Spain & 104 & 2.03 \\
\hline
\end{tabular}

However, the number of patents does not necessarily represent the technical power of a nation, and the nations with patents accepted may not be the source nations of the technology. In addition, a large number of patents does not necessarily represent high quality. For example, China had 1559 patents, which accounted for about $30 \%$ of global CSP patents, but the number of invention patents was just 909 , which was less than $60 \%$ of the Chinese patents. In addition, only $12 \%$ of the Chinese patents (185 patents) have applied for international patent protection, and the patent invalidation rate was $40 \%$.

\subsection{Analysis of Organizations}

\subsubsection{Main Organizations Producing CSP Papers}

The main organizations producing CSP papers are shown in Figure 4. Figure 4 indicates that there are 15 research institutions or universities producing more than 50 papers in the CSP field. These institutions are from China (5), Spain (3), the USA (2), India (1), Germany (1), France (1), Greece (1), and Iran (1). More than 100 papers have been published by the Chinese Academy of Sciences, Xi'an Jiaotong University, and the Indian Institute of Technology.

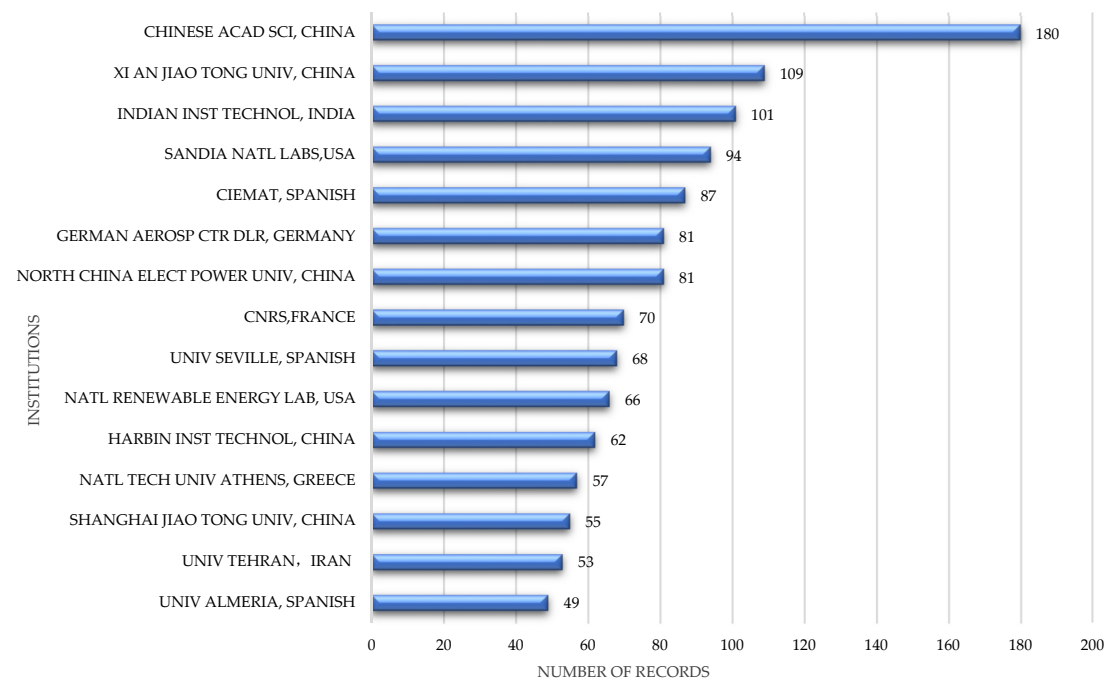

Figure 4. Main organizations producing CSP papers.

\subsubsection{Main Organizations Applying for CSP Patents}

Figure 5 shows the main applicants for CSP patents. There are 15 institutions with more than 30 patents in the CSP field.

Figure 5 indicates that these organizations are from Japan (4), the USA (3), China (3), Germany (2), France (2), and Spain (1). Thirteen of these organizations are companies, and only the German Aerospace Center (DRL) and the Institute of Electrical Engineering and the Chinese Academy of Sciences (IEE, CAS) 
are research institutions. These two research institutions have also produced large numbers of CSP papers. DLR has rich experience in CSP research and development, and has focused on research into molten salt storage in CSP power stations. The establishment of the Yanqing experimental solar-thermal power plant in 2012 by IEE, CAS marked the emergence of China as the fourth country to master CSP technology, after the USA, Germany, and Spain.

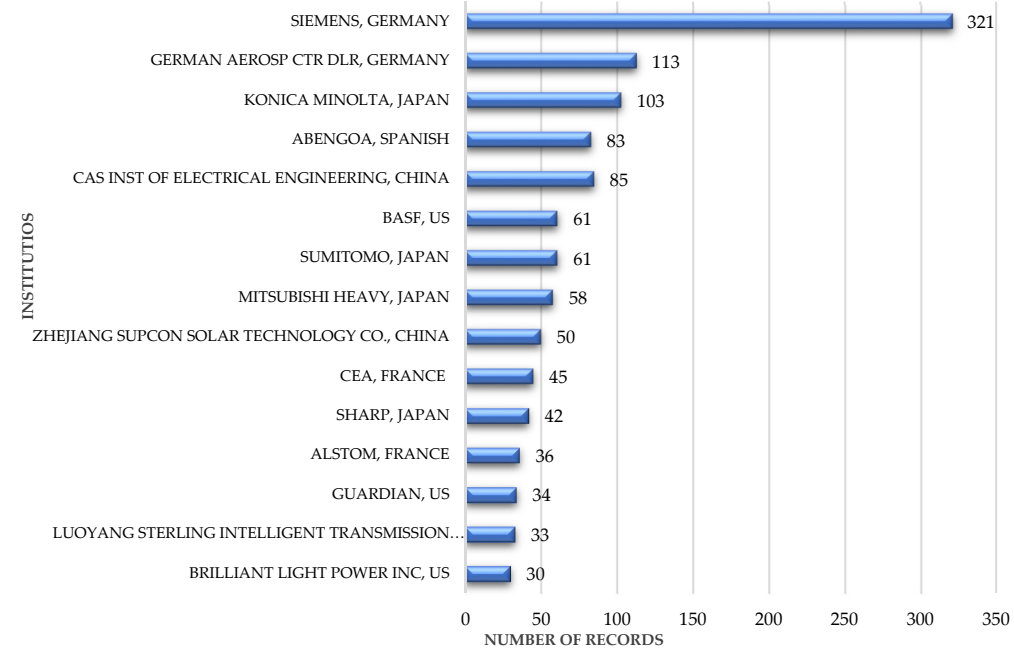

Figure 5. Main CSP patent applicants.

\subsection{Technology Trend Analysis}

\subsubsection{Main Research Topics of CSP Papers}

In this study, VOSviewer, a scientific mapping tool, was used to analyze the keyword clustering of SCI papers published in the past five years (2015-2019) in the field of CSP and to build a knowledge map (network) based on the word co-occurrence matrix, which is shown in Figure 6. Each node represents a keyword, with a larger node representing a keyword with a higher frequency. An edge between two nodes represents the co-occurrence frequency of keywords, with a thicker line corresponding to a higher frequency. The distance between two nodes represents the relationship between keywords, with a a shorter distance representing a higher similarity. The colors were assigned through clustering based on the occurrence of words describing the topics, and each color represents a topic cluster [52].

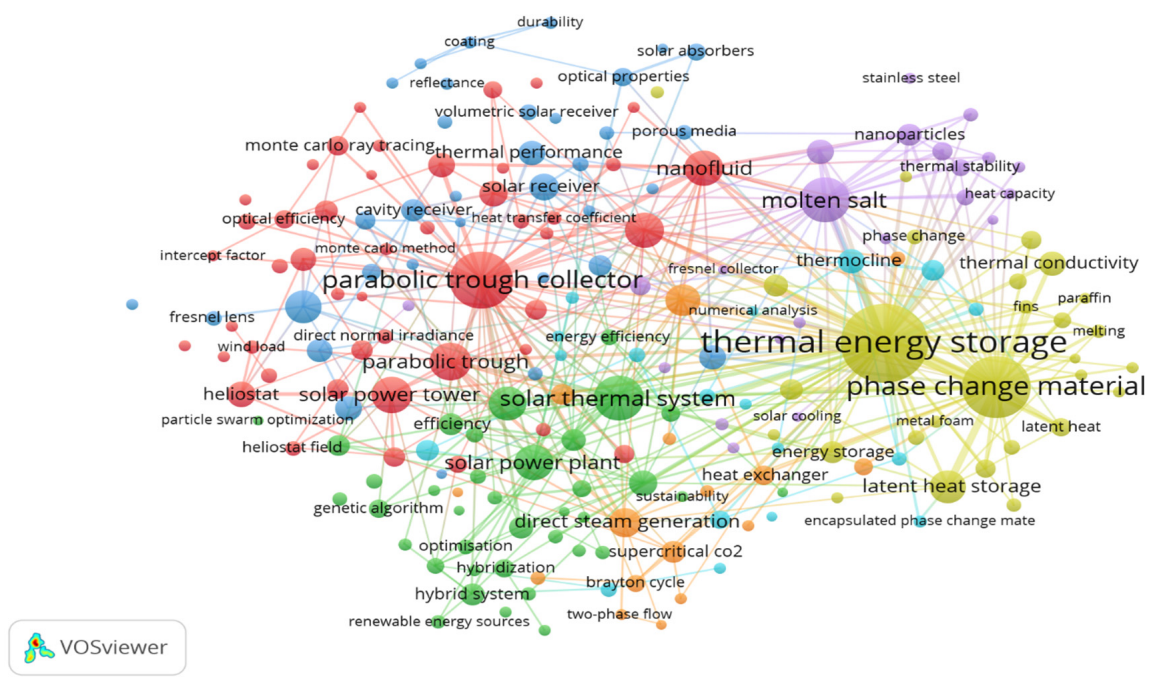

Figure 6. Research topics of CSP papers. 
The topic clustering analysis of SCI paper keywords in the CSP field shows that CSP technology research has focused on four major research categories, i.e., the collector field, solar thermal system, thermal energy storage (TES), and CSP generation systems and equipment. Every category is related to many aspects, and the four categories are related to each other according to the performance of the overall CSP system. For this, researchers have studied the optimization of the collector field, the receiver of the power tower, the receiver tube of the parabolic trough or linear Fresnel, the performance of heat transfer, thermal energy storage (including HTF and thermal storage material), molten salt materials and thermophysical properties, CSP power systems and equipment, and so on.

For a proposed 50-MW parabolic trough plant with 4-h thermal storage and a composition of investment cost over the construction period [53], the solar collector system cost makes up $43 \%$ of the investment cost over the construction period. Reducing the cost of collector is the key point to make CSP plant competitive with other renewable energy plants. Figure 6 illustrates that many studies on the parabolic trough collector have been published. Among these publications, the optimization of structural design of the parabolic trough and linear Fresnel collector have had a large volume. New methods, such as using raying tracking and shape measurement, have been developed to improve the concentrating efficiency. In addition to numerical simulation and experimental on mechanical performance, wind resistant and seismic resistance have also been also investigated.

The knowledge mapping of papers also indicates that solar thermal system research has focused on simulation and experimental research on building up new receiver model, heat transfer performance including conversion efficiency of light-heat, exergy efficiency, thermodynamics of materials using in the cavity receiver, particle receivers, and parabolic trough receivers. At the same time, dynamic simulation with the collector and receiver has been shown to increase the overall performance.

The thermal storage system is the biggest difference between photothermal and photovoltaic systems. TES can make CSP unique and dispatchable when mixed with other inexhaustible sources of energy [53]. At present, more than one-third of the installed CSP plants have thermal storage systems [54]. In the map, the largest proportion (about $20 \%$ ) is accounted for by research on TES systems, including thermal fluids, thermal storage materials, different kinds of thermal storage systems, and thermal storage performance. Packed-bed TES with solid material as thermal storage materials and two tanks TES with molten salts as thermal storage materials are the most popular TES in commercial CSP, and papers on these technologies are quickly increasing in number. In order to improve the storage density, phase change material (PCM) such as metal PCM, organic PCM, and inorganic PCM have been investigated. The solar thermal system and thermal storage system are related with HTF.

The SCI papers on overall performance analyses of CSP systems increased in number with the operation of commercial power stations, accounting for about $11 \%$ of all SCI papers. With the development of CSP from the first generation (with water/steam as HTF) to fourth generation (with high temperature particles as HTF), research on the performance of various power generation cycles is also increasing year by year, reaching $14.4 \%$ of the published SCI papers.

\subsubsection{Main Technical Topics of CSP Patents}

In this study, topic clustering analysis of titles and abstracts of CSP patents in the most recent five years (2015-2019) was conducted on the incoPat database platform, and a 3D "patent sand table" was drawn by a semantic clustering algorithm, as shown in Figure 7. Each sand dune represents a technical theme. A larger sand dune indicates a larger number of patents. The distance between sand dunes represents the relevance between themes: a shorter distance corresponds to a higher relevance.

The clustering results show that CSP patents focused on four large categories: Concentrator, heat receiver, thermal energy storage, and power block of CSP. These four categories were divided into 15 small categories. In addition, the classification of heat transfer materials and thermal storage materials was conducted, according to the difference between heat transfer and thermal storage in CSP technology. Table 5 illustrates the patents number of every small categories. 


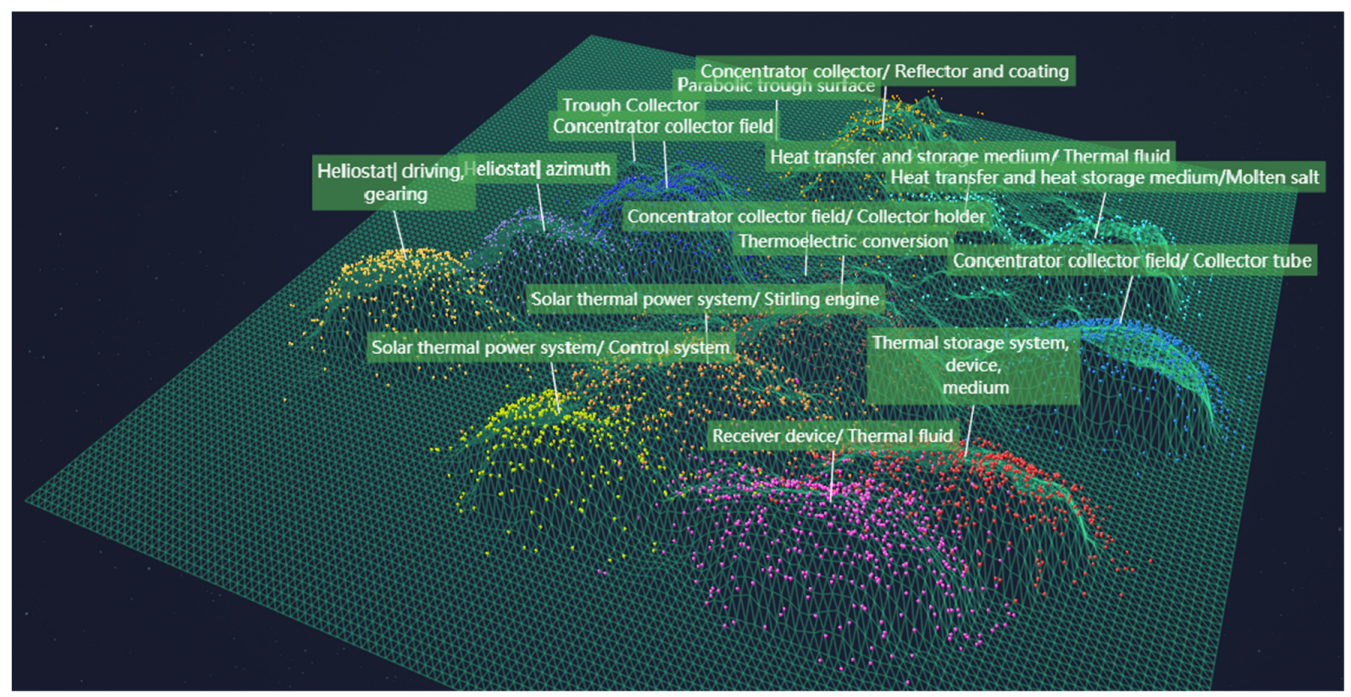

Figure 7. Technical topics of CSP patents.

Table 5. CSP patents number for each category.

\begin{tabular}{ccc}
\hline Large Categories & Small Categories & Patents Number \\
\hline \multirow{4}{*}{ Concentrator } & Heliostat/Driving, gearing & 407 \\
& Heliostat/Azimuth & 331 \\
& Concentrator collector field/Concentrator calibration & 339 \\
& Trough Collector & 491 \\
& Concentrator collector field/Reflector and coating & 375 \\
& Concentrator collector field/Parabolic trough surface & 189 \\
& Concentrator collector field/Concentrator, collector holder & 101 \\
\hline \multirow{2}{*}{ Heat receiver } & Concentrator collector field/Collector tube & 471 \\
& Receiver/Receiver device/Thermal fluid & 558 \\
\hline \multirow{3}{*}{ Heat transfer and thermal energy storage } & Heat transfer and heat storage medium/Molten salt & 116 \\
& Heat transfer and heat storage medium/Thermal fluid & 128 \\
& Thermal storage system, device, medium & 440 \\
\hline \multirow{2}{*}{ Power block of CSP } & Solar thermal power system/Control system & 423 \\
& Solar thermal power system/Stirling engine & 461 \\
& thermoelectric conversion & 70 \\
\hline
\end{tabular}

Figure 7 shows that the volume of patents on concentrators and receivers is the largest. This mainly involves seven patented technologies, such as the drive, transmission, and azimuth of heliostats, the tracking and calibration of collectors, and various new types of heat receiver. The trends of patents are related with the CSP developing trend. For an energy technology, LCOE is the driving force behind technological development. At present, the investment cost of concentrators and receivers has exceeded $50 \%$ of the total cost of CSP systems. Therefore, the development of new equipment systems is a key issue in reducing investment costs and LCOE, as well as improving efficiency. The patented technologies for heat receivers and heat energy storage mainly focus on receivers, thermal storage systems, HTF (such as molten salt receivers), and thermal storage materials (such as phase-change and solid thermal storage materials), to meet the development requirements of heat transfer and thermal storage for new generation CSP technology. CSP power generation system patents mainly focus on the control system, Stirling engine, and thermoelectric conversion to improve the efficiency and stability of CSP systems.

\section{Conclusions and Prospects}

Bibliometric analysis and knowledge mapping, based on papers and patents, was an effective method to reveal the current status of, and trends in, technical research and applications. In this paper, topic discovery and clustering were studied using bibliometric, social network analysis, and information visualization technology, based on the WoS database (SCI-Expanded) and the incoPat global patent database. 
The technology searched for papers and patents related to CSP technology to reveal the development trends of CSP technology and provide the references for related technical layout and hotspot tracking.

Bibliometrics was used to analyze papers and patents related to CSP technology around the world. It can be observed, from the annual publication trends of CSP papers, that the output of SCI papers has maintained stable growth in the past decade, and there is a trend of continuous growth in the future, with a high development momentum. However, the number of patents has shown a significant downward trend in the past five years, and CSP, which is in the initial stage of commercialization, still needs technological breakthroughs. Through the analysis of research fields and technology distribution, it can be observed that CSP technology — combined with thermodynamic engineering, control technology, physics, chemistry, materials, and multidisciplinary integration and innovation-can become an effective path for CSP technology development in the future. Through the analysis of countries, regions, and organizations with high-yield publications and patent applications, it can be observed that these countries (i.e., the USA, Spain, Germany, and Japan) continue to lead the innovation and application of CSP. Meanwhile, China and India are rising rapidly, playing an increasingly important role in the field of CSP.

Through bibliometric analysis and topic clustering of papers and patents in the CSP field, some trends of CSP technology research and development are evident:

1. There is a great need to develop the research of high-temperature receivers (solid receivers and particle receivers) and phase-change thermal storage systems (cascade phase-change thermal storage and metal phase-change thermal storage). From the perspective of materials, some new receivers, HTFs, and thermal storage materials will be developed. In addition, the research on heat transfer and heat storage fluids, and their thermophysical properties will be conducted.

2. The trend is changing gradually from local research on all components toward research on system integrity. Research on light-heat-electricity conversion efficiency, economic electrical performance, environmental impact, and other global aspects of CSP is gradually increasing.

3. Research on the key components of CSP has been conducted, ranging from research on the overall performance of the components to studies of their detailed parameters, through modeling, simulation, and experiment. This has allowed optimization of the various components and the overall system, to improve the overall performance of the CSP system.

4. The trend is developing from a single technology to multi-energy complementary systems, such as the combination of solar thermal power and photovoltaic power generation.

The development and competitiveness of any technology are affected not only by the technology itself, but also by multiple factors, such as the ecological environment, social environment, political environment, and economic environment. CSP technology is a growing field with application-oriented features. Moreover, its development has great significance for the sustainable development of human society. It should be pointed out that the conclusions of this paper come from two databases-WoS (SCI-Expanded) and incoPat-which do not fully include papers published in all forms and languages around the world, and therefore the conclusions have certain limitations. However, considering that these two data sources are authoritative databases of global scientific literature and patents, the conclusions are similarly representative.

Author Contributions: Conceptualization, methodology and writing—original draft preparation, Q.C.; formal analysis and writing — original draft preparation, Y.W.; Resources, J.Z;; writing-review and editing, Z.W. All authors have read and agreed to the published version of the manuscript.

Funding: This research was funded by National Key Research and Development Program Key Project on “key basic problems of supercritical $\mathrm{CO}_{2}$ solar thermal power generation" (2018YFB1501005) from Ministry of Science and Technology of China.

Acknowledgments: This research was also supported by Guangdong Innovative and Entrepreneurial Research Team Program (No. 2013N070) from the Guangdong Provence of China.

Conflicts of Interest: The authors declare no conflicts of interest. 


\section{References}

1. McPherson, M.; Mehos, M.; Denholm, P. Leveraging concentrating solar power plant dispatchability: A review of the impacts of global market structures and policy. Energy Policy 2020, 139, 111335. [CrossRef]

2. Hasan, M.H.; Mahlia, T.M.I.; Nur, H. A review on energy scenario and sustainable energy in Indonesia. Renew. Sustain. Energy Rev. 2012, 16, 2316-2328. [CrossRef]

3. Achkari, O.; El Fadar, A. Latest developments on TES and CSP technologies-Energy and environmental issues, applications and research trends. Appl. Therm. Eng. 2020, 167, 114806. [CrossRef]

4. Pazheri, F.R.; Othman, M.F.; Malik, N.H. A review on global renewable electricity scenario. Renew. Sustain. Energy Rev. 2014, 31, 835-845. [CrossRef]

5. Princiotta, F.T.; Loughlin, D.H. Global climate change: The quantifiable sustainability challenge. J. Air Waste Manag. Assoc. 2014, 64, 979-994. [CrossRef]

6. Aman, M.M.; Solangi, K.H.; Hossain, M.S.; Badarudin, A.; Jasmon, G.B.; Mokhlis, H.; Bakar, A.H.A.; Kazi, S.N. A review of Safety, Health and Environmental (SHE) issues of solar energy system. Renew. Sustain. Energy Rev. 2015, 41, 1190-1204. [CrossRef]

7. Antonanzas, J.; Jimenez, E.; Blanco, J.; Antonanzas-Torres, F. Potential solar thermal integration in Spanish combined cycle gas turbines. Renew. Sustain. Energy Rev. 2014, 37, 36-46. [CrossRef]

8. González-Roubaud, E.; Pérez-Osorio, D.; Prieto, C. Review of commercial thermal energy storage in concentrated solar power plants: Steam vs. molten salts. Renew. Sustain. Energy Rev. 2017, 80, $133-148$. [CrossRef]

9. Raboaca, M.S.; Badea, G.; Enache, A.; Filote, C.; Rasoi, G.; Rata, M.; Lavric, A.; Felseghi, R.A. Concentrating Solar Power Technologies. Energies 2019, 12, 1048. [CrossRef]

10. Izquierdo, S.; Montañés, C.; Dopazo, C.; Fueyo, N. Analysis of CSP plants for the definition of energy policies: The influence on electricity cost of solar multiples, capacity factors and energy storage. Energy Policy 2010, 38, 6215-6221. [CrossRef]

11. European Solar Thermal Electricity Association Solar Thermal Electricity Global Outlook 2016. Available online: http://www.greenpeace.org/archive-nternational/Global/international/publications/climate/2016/SolarThermal-Electricity-Global-Outlook-2016.pdf (accessed on 11 April 2016).

12. Wang, Z.F. Introduction. Solar Thermal Power Station Design, 1st ed.; Dai, Y.H., Zheng, Y.Y., Eds.; Chemical Industry Press: Beijing, China, 2014.

13. How CSP Works: Tower, Trough, Fresnel or Dish. Available online: https://www.solarpaces.org/how-csp-works (accessed on 15 July 2019).

14. The European Academies Science Advisory Council (EASAC). Concentrating Solar Power: Its Potential Contribution to a Sustainable Energy future. Available online: https://www.easac.eu/fileadmin/Reports/ Easac_CSP_Web-Final.pdf (accessed on 20 April 2018).

15. Vogel, W.; Kalb, H. Large-Scale Solar Thermal Power: Technologies, Costs and Development; Wiley: Hoboken, NJ, USA, 2010.

16. International Energy Agency (IEA) CSP Projects Around the World. Available online: https://www.solarpaces. org/csp-technologies/csp-projects-around-the-world/ (accessed on 4 March 2020).

17. Jafrancesco, D.; Fontani, D.; Francini, F.; Sansoni, P. Evaluation of the Spot Shape on the Target for Flat Heliostats. Energies 2018, 11, 1621. [CrossRef]

18. Pei, G.; Li, G.; Su, Y.; Ji, J.; Riffat, S.; Zheng, H. Preliminary Ray Tracing and Experimental Study on the Effect of Mirror Coating on the Optical Efficiency of a Solid Dielectric Compound Parabolic Concentrator. Energies 2012, 5, 3627. [CrossRef]

19. Zhang, D.; You, G. Method of Adjusting Off-Axis Parabolic Mirror System Using Lens Confocal, Involves Adding Lens to Optical Circuit, Using Lens confocal Alignment Method and Moving Off-axis Parabolic Mirror by Flat Mirror Instead of Off-Axis Parabolic Mirror. Patent CN110764272-A, 7 February 2020.

20. Kaluba, V.S.; Mohamad, K.; Ferrer, P. Experimental and simulated performance of hot mirror coatings in a parabolic trough receiver. Appl. Energy 2020, 257, 114020. [CrossRef] 
21. Ambrosini, A.; Lambert, T.N.; Boubault, A.; Hunt, A.; Davis, D.J.; Adams, D.; Hall, A.C. Thermal Stability of Oxide-Based Solar Selective Coatings for Csp Central Receivers. In Proceedings of the ASME 2015 9th International Conference on Energy Sustainability collocated with the ASME 2015 Power Conference, the ASME 2015 13th International Conference on Fuel Cell Science, Engineering and Technology, and the ASME 2015 Nuclear Forum, San Diego, CA, USA, 28 June-2 July 2015.

22. You, D.C.; Yu, Q.; Wang, Z.F.; Sun, F.H. Study on Optimized Dispatch and Operation Strategies for Heliostat Fields in a Concentrated Solar Power Tower Plant. Energies 2019, 12, 4544. [CrossRef]

23. Islam, M.; Miller, S.; Yarlagadda, P.; Karim, A. Investigation of the Effect of Physical and Optical Factors on the Optical Performance of a Parabolic Trough Collector. Energies 2017, 10, 1907. [CrossRef]

24. Liu, D.; Cao, Y.; Wang, W.; Song, T.; Chen, Q. Terahertz Long-Distance Quasi-Optical Transmission System, has Mirror Group Provided with Quasi-Parabolic Mirror, and Plane Mirror for Adjusting Optical Path of Quasi-Parabolic Mirror and Perturbed Plane Mirror to Perform Phase Correction. Patent CN110737082-A, 31 January 2020.

25. Besbes, M.; Bru, H.; Ben-Abdallah, P.; Langlais, M.; Langlais, I.M. Solar Thermal Receiver for Concentrated Solar Thermal Energy Plant for Utility-Scale Application, has Light Absorber Comprising metallic Nanoparticles in Host Material that is Transparent in Absorbing Range of Light Absorber. Patent WO2015049384-A1, 9 April 2015.

26. Arjomandi, M.; Nathan, G.J.; Chinnici, A.; Tian, Z. Solar Receiver for Exposing Heat Absorbing Particles to Concentrated Solar Radiation, has Inlet unit Communicating with Chamber for Introduction of Inflow into Section of Chamber, Where Flow Establishes Flow Field Including Vortex Structure. Patent WO2017024338, 16 February 2017.

27. Avila-Marin, A.L.; Fernandez-Reche, J.; Martinez-Tarifa, A. Modelling strategies for porous structures as solar receivers in central receiver systems: A review. Renew. Sustain. Energy Rev. 2019, 111, 15-33. [CrossRef]

28. Cagnoli, M.; de la Calle, A.; Pye, J.; Savoldi, L.; Zanino, R. A CFD-supported dynamic system-level model of a sodium-cooled billboard-type receiver for central tower CSP applications. Sol. Energy 2019, 177, 576-594. [CrossRef]

29. Ali, B.H.; Gilani, S.I.; Al-Kayiem,H.H.; Ali, B.H.; Gilani, S.I.; Al-Kayiem, H.H.; Karim, Z.A.A.; Baharudin, Z.H.; Basrawi, M.F.; Rahman, M.M.; et al. Mathematical Modeling of a developed Central Receiver Based on Evacuated Solar Tubes. EDP Sci. 2016, 38, 02005. [CrossRef]

30. Bossmann, H.; Hasani, M.B. Central Solar Receiver Heat Exchanger Tube for Solar Heat Transfer System, Has Metal-Ceramic Coating that Includes Metal Matrix with Ceramic Phases Dispersed in Metal Matrix and is Disposed Along Surface of Heat Exchanger Tube. Patent US2018017290, 9 August 2018.

31. Almendros-Ibáñez, J.A.; Fernández-Torrijos, M.; Díaz-Heras, M.; Belmonte, J.F.; Sobrino, C. A review of solar thermal energy storage in beds of particles: Packed and fluidized beds. Sol. Energy 2019, 192, 193-237. [CrossRef]

32. Árpád, I. Investigation of Sensible Heat Storage and Heat Insulation in the Exploitation of Concentrated Solar Energy. Hungrian J. Ind. Chem. 2011, 39, 5.

33. Yang, B.; Wang, Y.; Bai, F.W.; Wang, Z.F. Experimental and numerical investigation of a packed-bed thermal energy storage device. In Proceedings of the International Conference on Concentrating Solar Power and Chemical Energy Systems, Abu Dhabi, UAE, 11-14 October 2016.

34. Pacheco, J.E.; Showalter, S.K.; Kolb, W.J. Development of a Molten-Salt Thermocline Thermal Storage System for Parabolic Trough Plants. J. Sol. Energy Eng. 2002, 124, 153-159. [CrossRef]

35. Brosseau, D.; Kelton, J.W.; Ray, D.; Edgar, M.; Chisman, K.; Emms, B. Testing of Thermocline Filler Materials and Molten-Salt Heat Transfer Fluids for Thermal Energy Storage Systems in Parabolic Trough Power Plants. J. Sol. Energy Eng. 2005, 127, 109-116. [CrossRef]

36. Bindra, H.; Bueno, P.; Morris, J.F. Sliding flow method for exergetically efficient packed bed thermal storage. Appl. Therm. Eng. 2014, 64, 201-208. [CrossRef]

37. Mao, Q. Recent developments in geometrical configurations of thermal energy storage for concentrating solar power plant. Renew. Sustain. Energy Rev. 2016, 59, 320-327. [CrossRef]

38. Palacios, A.; Barreneche, C.; Navarro, M.E.; Ding, Y. Thermal energy storage technologies for concentrated solar power-A review from a materials perspective. Renew. Energy 2019, in press. [CrossRef]

39. Ogunmodimu, O.; Okoroigwe, E.C. Concentrating solar power technologies for solar thermal grid electricity in Nigeria: A review. Renew. Sustain. Energy Rev. 2018, 90, 104-119. [CrossRef] 
40. DeLovato, N.; Sundarnath, K.; Cvijovic, L.; Kota, K.; Kuravi, S. A review of heat recovery applications for solar and geothermal power plants. Renew. Sustain. Energy Rev. 2019, 114, 109329. [CrossRef]

41. Norwood, Z.; Goop, J.; Odenberger, M. The Future of the European Electricity Grid Is Bright: Cost Minimizing Optimization Shows Solar with Storage as Dominant Technologies to Meet European Emissions Targets to 2050. Energies 2017, 10, 2080. [CrossRef]

42. Behar, O. Solar thermal power plants-A review of configurations and performance comparison. Renew. Sustain. Energy Rev. 2018, 92, 608-627. [CrossRef]

43. Bilgili, M.; Ozbek, A.; Sahin, B.; Kahraman, A. An overview of renewable electric power capacity and progress in new technologies in the world. Renew. Sustain. Energy Rev. 2015, 49, 323-334. [CrossRef]

44. Islam, M.T.; Huda, N.; Abdullah, A.B.; Saidur, R. A comprehensive review of state-of-the-art concentrating solar power (CSP) technologies: Current status and research trends. Renew. Sustain. Energy Rev. 2018, 91, 987-1018. [CrossRef]

45. Zhuang, X.; Xu, X.; Liu, W.; Xu, W. LCOE Analysis of Tower Concentrating Solar Power Plants Using Different Molten-Salts for Thermal Energy Storage in China. Energies 2019, 12, 1394. [CrossRef]

46. Otte, E.; Rousseau, R. Social network analysis: A powerful strategy, also for the information sciences. J. Inf. Sci. 2002, 28, 441-453. [CrossRef]

47. Chen, D.; Liu, Z.; Luo, Z.; Webber, M.; Chen, J. Bibliometric and visualized analysis of emergy research. Ecol. Eng. 2016, 90, 285-293. [CrossRef]

48. Zou, X.; Long, W.; Le, H. Visualization and analysis of mapping knowledge domain of road safety studies. Accid. Anal. Prev. 2018, 118, 131-145. [CrossRef]

49. Nazir, H.; Batool, M.; Osorio FJ, B.; Isaza-Ruiz, M.; Xu, X.; Vignarooban, K.; Phelan, P.; Kannan, A.M. Recent developments in phase change materials for energy storage applications: A review. Int. J. Heat Mass Transf. 2019, 129, 491-523. [CrossRef]

50. Pauna, V.; Buonocore, E.; Renzi, M.; Russo, G.; Franzese, P. The issue of microplastics in marine ecosystems: A bibliometric network analysis. Mar. Pollut. Bull. 2019, 149, 110612. [CrossRef]

51. Chen, Q.M.; Zheng, C.X.; Li, H.Y. Analysis on the international development trend of energy storage technology based on bibliometrics. Energy Storage Sci. Technol. 2020, 9, 10.

52. Colares, G.S.D.O.N.; Wiesel, P.G.; Oliveira, G.A.; Lemos, P.H.Z.; da Silva, F.P.; Lutterbeck, C.A.; Kist, L.T.; Machado, E.L. Floating treatment wetlands: A review and bibliometric analysis. Sci. Total Environ. 2020, 714, 136776. [CrossRef]

53. Zhao, Z.Y.; Chen, Y.L.; Thomson, J.D. Levelized cost of energy modeling for concentrated solar power projects: A China study. Energy 2017, 120, 117-127. [CrossRef]

54. The Potential Role of Concentrating Solar Power within the Context of DOE's 2030 Solar Cost Targets. Available online: https://www.osti.gov/servlets/purl/1491726 (accessed on 18 January 2019). 